NATIONAL

Center for Analysis of Longitudinal Data in Education Research

TRACKING EVERY STUDENT'S LEARNING EVERY YEAR

A program of research by the American Institutes for Research with Duke University, Northwestern University, Stanford University, University of Missouri-Columbia, University of Texas at Dallas, and University of Washington

商AIR

Is It Worth It? Postsecondary

Education and Labor Market

Outcomes for the

Disadvantaged

B E N J A M I N B A C K E S

HARRY J. HOLZER

ERIN D U N L O P VELEZ 


\section{Is It Worth It? Postsecondary Education and Labor Market Outcomes for the Disadvantaged}

Benjamin Backes

American Institutes for Research

Harry J. Holzer

Georgetown University and American Institutes for Research

Erin Dunlop Velez RTI International 


\section{Contents}

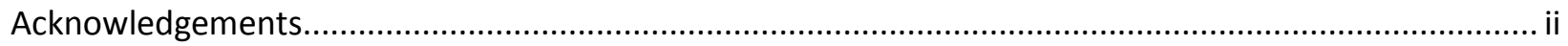

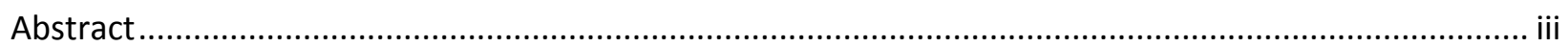

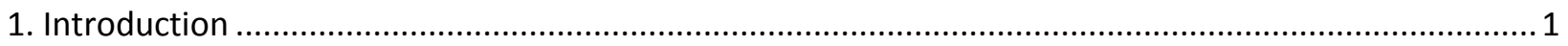

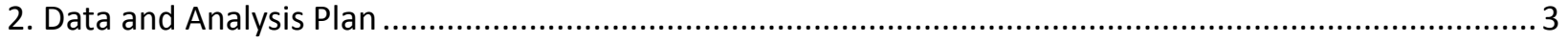

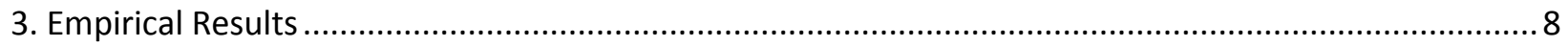

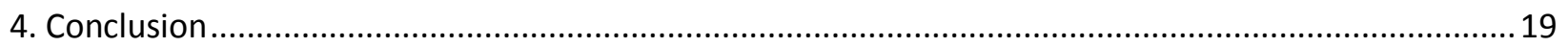

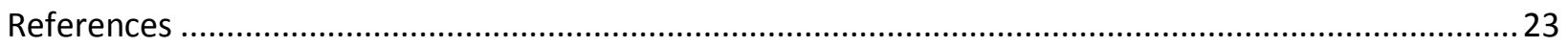

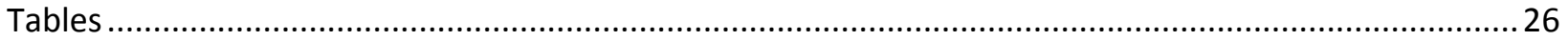




\section{Acknowledgements}

This paper is part of the Postsecondary Education and Labor Market Program at the Center for the Analysis of Longitudinal Data in Education Research (CALDER) at AIR. We thank Tiffany Chu and Kennan Cepa for excellent research assistance. This research was supported by the CALDER postsecondary initiative, funded through grants provided by the Bill and Melinda Gates Foundation and the Smith Richardson Foundation to the American Institutes of Research.

CALDER working papers have not gone through final formal review and should be cited as working papers. They are intended to encourage discussion and suggestions for revision before final publication.

CALDER • American Institutes for Research

1000 Thomas Jefferson Street N.W., Washington, D.C. 20007

202-403-5796 • www.caldercenter.org 


\section{Is It Worth It? Postsecondary Education and Labor Market Outcomes for the Disadvantaged}

Benjamin Backes, Harry J. Holzer, and Erin Dunlop Velez

CALDER Working Paper No. 117

September 2014

\section{Abstract}

In this paper we examine a range of postsecondary education and labor market outcomes, with a particular focus on minorities and/or disadvantaged workers. We use administrative data from the state of Florida, where postsecondary student records have been linked to UI earnings data and also to secondary education records. Our main findings can be summarized as follows: 1) Gaps in secondary school achievement can account for a large portion of the variation in postsecondary attainment and labor market outcomes between the disadvantaged and other students, but meaningful gaps also exist within achievement groups, and 2) Earnings of the disadvantaged are hurt by low completion rates in postsecondary programs, poor performance during college, and not choosing high-earning fields. In particular, significant labor market premia can be earned in a variety of more technical certificate and Associate (AA) programs, even for those with weak earlier academic performance, but instead many disadvantaged (and other) students choose general humanities programs at the AA (and even the Bachelor's or BA) level with low completion rates and low compensation afterwards. A range of policies and practices might be used to improve student choices as well as their completion rates and earnings. 


\section{Introduction}

It is, by now, well-known that rewards to college degrees (especially at the BA level) have grown quite large in the U.S. labor market. Indeed, for young people growing up in disadvantaged families, obtaining a college degree is the surest way to achieve upward mobility for themselves and their families (Issacs, 2007; Haskins et al., 2009). Thus, the incentives for low-income young people to pursue higher education have become very strong. Even if only an associate degree or a certificate is achieved, the labor market rewards for young people remain quite substantial (Holzer and Dunlop, 2013).

Yet, in spite of these incentives, young economically disadvantaged students lag substantially behind their middle- and upper-income counterparts in achieving postsecondary credentials, and minorities continue to lag behind white students. While rates of college enrollment have risen for all groups in recent years, college completion rates, especially among minorities and the disadvantaged, remain low (Bound et al., 2010; Holzer and Dunlop, 2013), and gaps in postsecondary attainment between income groups in the U.S. have grown in recent decades (Bailey and Dynarski, 2011). In addition, while the average value of a college degree in the labor market is high, the concentration of young people in high-earning fields (like science/technology/engineering/math, or STEM) are not as high as we might expect, especially given the meaningful differences in earnings we observe across fields. In particular, women, minorities and the poor are less likely to earn a credential in these high-earning fields.

Why are disadvantaged and/or minority students less likely than their white/middle-class counterparts to earn postsecondary credentials? In part, this is because of the academic achievement gap between these students and their more advantaged peers. This gap emerges early in life, and tends to become larger as students progress through school (Reardon, 2011). But even adjusting for prior achievement, disadvantaged young people lag behind others in college completion and attainment. 
If the achievement gap does not fully explain this difference, what does? The research literature has identified information gaps, college costs and lack of full-time attendance as some of the factors that impair the success rates of disadvantaged young people in college (Bound et al., 2010; Hoxby and Turner, 2013). Because of these factors, young disadvantaged students attend lower-quality colleges and universities, with lower completion rates, and their completion rates within the same institutions are lower than that of more advantaged students as well.

But many questions remain unanswered about the relative magnitudes and the interaction of factors that contribute to the lack of postsecondary success for disadvantaged students. For example, how important is disadvantaged students' choice of major at each level of education? Adjusting for high school achievement, by how much does their performance in college - as measured by courses taken, grades attained, credits earned, and ultimately program completion - lag behind those of students who are not disadvantaged? And how much do these factors account for their lower labor market earnings, as opposed to other barriers that impede the accumulation of valuable labor market experience (Johnson and Neal, 1998)?

Answers to these questions are important if we want to design effective programs and policies to better assist disadvantaged students in their college experiences; and such answers require detailed longitudinal micro data on students, their educational institutions and experiences, and on labor market outcomes. While some such information is available in existing longitudinal survey datasets on young people - such as the National Educational Longitudinal Study (NELS), High School and Beyond (HSB) or the National Longitudinal Survey of Youth (NSLY) - administrative data on students provides such detailed information on every course they have taken and on all academic outcomes achieved for every student who ever attended a public school in the relevant years. Until recently such data have not existed at the state level, but in several states are now becoming available. This enables researchers to 
address previously unexplored questions about the experience and outcomes associated with disadvantaged students in a number of contexts. ${ }^{1}$

In this paper, we use administrative data from the state of Florida to analyze the college and labor market experiences of two cohorts of young people. We are able to extend the current literature on the returns to college credentials in several important ways. First, the students in our data graduated high school between 2000 and 2002, making them a more recent cohort then many previous studies. Second, our large sample size, over 210,000 students, allows us to measure heterogeneous effects with precision. Third, unlike many other recent studies, we also have access to secondary school data, so we can control for earlier achievement. Finally, this paper focuses on disadvantaged students in particular, a large and growing fraction of the U.S. postsecondary market.

Below, we describe our data and analysis in Part II of the paper, present the empirical results in Part III, and present our conclusions and their general implications for further research and policy in Part IV.

\section{Data and Analysis Plan}

\subsection{Data Overview}

To create our sample, we merge together three large administrative student-level data sets from the state of Florida: secondary school data, postsecondary data, and unemployment earnings data, the latter of which provides earnings information for nearly all Florida residents. ${ }^{2}$ Linked together by a unique individual identifier, we are able to follow students from eighth grade through college (and graduate school) and their entry into the labor force, provided the student does not leave the state of Florida. Our data provide large sample sizes unavailable in national surveys, offer rich information to

\footnotetext{
${ }^{1}$ See Jacobson and Mokher (2009), Jepsen et al. (2014) and Kreisman et al. (2013).

2 The unemployment insurance records do not include information on several small categories of employees including self-employed and federal workers.
} 
account for selection based on ability (e.g. Lovenheim and Reynolds, 2011), and provide detailed information on several important outcome measures.

The data for this paper follow two cohorts of students. The first wave comprises all students who began 10th grade at a Florida public school in 1997-98. The second wave consists of all students who began 8th grade in 1997-1998. The data set contains observations as recent as $2011-12$, so we observe 10-12 years of postsecondary and labor market outcomes.

The secondary student-level data include student demographic information (race, gender, and limited English proficiency status) and we use eligibility for free- or reduced-price lunch (FRL) as a measure of family income. In addition, we have data on courses taken, course grades, GPA, and standardized test scores (such as the Florida Comprehensive Assessment Test, or FCAT). These serve as important controls and allow for analysis of heterogeneous treatment effects.

Our rich postsecondary information comes from public colleges and universities in Florida, and includes date and institution of each enrollment instance, courses taken at each institution and grades received, cumulative credits earned, field of study, and degree attainment. We utilize this data to measure both intermediate postsecondary outcomes (such as major choice) and terminal postsecondary outcomes (such as highest degree earned).

Finally, we merge our data with quarterly wage information from employer reports to Florida's Unemployment Insurance (UI) office. These data are collected during high school and for five years after a student leaves her last educational institution.

The main drawback of our data is their limitation to a single state, which could have implications for both generalizability to other states and attrition (since individuals leaving the state are not observed). For generalizability, this drawback is somewhat mitigated by Florida's large and diverse makeup. According to the Digest of Education Statistics, in 2008-2009, Florida ranked as the fourth largest state in terms of the number of graduates from public high schools. In addition, 22 percent of its 
high school graduates were black and 23 percent Hispanic, compared to national averages of 15 and 16 percent, respectively.

Although the data are limited to students who attend in-state public institutions, Florida has a relatively low out-migration rate for college-goers. Specifically, only 10 percent of Floridian first-time degree or certificate-seeking undergraduates attend college out of state. ${ }^{3}$ In addition, about $85 \%$ percent of first-time degree-seeking students attend a public, rather than private, institution in Florida. ${ }^{4}$ Therefore, we likely do not lose a large subset of our sample to private or out-of-state colleges. However, students who enroll in out-of-state or private colleges are more likely to come from higherincome families, are higher-performing students, and/or attend higher-quality institutions (Sapra, 2013). The potential downward bias in some of our estimates of enrollment, completion, and earnings due to missing student observations needs to be kept in mind as we review our results.

In addition, as many as half of all Florida higher education enrollees do not subsequently appear in the labor market data. This could be either because they have moved out of state for work or family reasons, or because they remain in state but do not join the labor market. Previous studies have found that $30-50 \%$ of males age $25-45$ work in a state other than their birth state, depending on their level of education, which is broadly consistent with the out-migration we observe. ${ }^{5}$ In addition, our own calculations using the American Community Survey find similar rates of mobility of college graduates who were born in Florida. Overall, rates of labor market participation appear lowest for those with the weakest observed skills in their high school years. ${ }^{6}$

A final limitation of the sample is its emphasis on traditional students: those whose postsecondary studies begin relatively soon after high school graduation. For example, if a student were

${ }^{3}$ Institute of Education Sciences. Digest of Education Statistics, Table 232. Retrieved May 21, 2014, from http://nces.ed.gov/programs/digest/d11/tables/dt11_232.asp ${ }^{4}$ Institute of Education Sciences. Digest of Education Statistics, Table 233. Retrieved May 21, 2014, from http://nces.ed.gov/programs/digest/d12/tables/dt12_233.asp ${ }^{5}$ Malamud and Wozniak (2008)

${ }^{6}$ For instance, in our oldest cohort, over $70 \%$ of those in the top achievement quartile appear in the labor market, whereas for the lowest quartile the comparable fraction is just $35 \%$. 
to go back to college outside the 10-12 year window for which we have data, this enrollment would not be captured. Thus, we miss out on this important component of the community college-going population.

We construct several variables from our administrative data. For example, for students who complete a degree, identifying degree earned and field of study is straightforward. However, students who enroll in postsecondary education but do not complete a degree could have had many fields of study throughout the course of their enrollment. Reasonable choices for "field of study" include first declared major, last declared major, or most frequently-observed major (by number of terms). In this paper, for those students who do not earn a degree, we consider their field of study to be their final declared major before exiting postsecondary schooling.

Finally, we count each quarter that an individual appears in the UI data as one quarter of work experience. When calculating tenure, we count each quarter of employment with a given employer, whether or not that employment is continuous. ${ }^{7}$ When examining labor market outcomes, we only consider observations following each individual's final term of postsecondary enrollment and only include students 18 years of age and older. Only those quarters with positive earnings are included in our computations. ${ }^{8}$

\subsection{Analysis Plan}

We begin our analysis by presenting summary data on differences in higher education and labor market outcomes between race/gender groups, and those who do and do not qualify for FRL. After establishing the basic facts on outcomes that need to be explained, we divide the students into quartiles

\footnotetext{
${ }^{7}$ Our measures of work experience and tenure do not count intermittent quarters with zero employment towards those measures.

${ }^{8}$ Researchers generally attribute quarters with zero earnings to labor supply decisions, in which the individual did not choose to join the labor force or could not find employment; however in our data another possible explanation is that the individual moved out of state. To assess whether not including short-term non-working spells is driving our results, we conduct a robustness check in which we impute earnings for individuals with 1-3 quarters of missing UI records in between observed employment spells. The results are robust to this imputation of zero earnings.
} 
based on their high school FCAT scores, and explore differences between these quartiles - which likely reflect their differences in early achievement - versus those differences within quartiles, which cannot be attributed to achievement gaps.

We then present results from regression equations of the following general form:

1) InEARN ${ }_{i k t}=f\left(E D_{i}, X_{i}, A_{C H I E V E}, \operatorname{EXP}_{i}, \operatorname{EXP}_{i}^{2}, \operatorname{TEN}_{i}, \operatorname{TEN}_{i}^{2}, \operatorname{COHORT}_{k}, \operatorname{TIME}_{t}\right)+u_{i k t}$

where InEARN denotes the natural log of quarterly earnings; ED denotes the highest level of education completed (either high school, a certificate, an AA degree, a BA degree, or higher); $\mathrm{X}$ measures race/ethnicity, gender, and family background; ${ }^{9}$ ACHIEVE measures high school achievement (FCAT math score) $i^{10}$ EXP and TEN reflect quarters of total labor market experience and job tenure with their current firm respectively (entering the equation in both linear and quadratic form); and COHORT and TIME denote cohort and year/quarter dummies. The individual person, cohort and year/quarter are denoted respectively by the subscripts $i, k$, and $t$. Missing values in achievement measures are measured as zeroes along with a " 1 " for a missing value dummy variable.

We use our measure of high school achievement to correct for selection into higher education, which is unobservable in most studies. Given the limited number of years in which we observe labor market outcomes for any individual, and since we primarily focus on earnings in the post-education period, we do not present estimates from models with individual fixed effects here. ${ }^{11}$

In some versions of the estimated equations, we control for the number of postsecondary credits earned if the student did not complete the degree program in which they had enrolled. In other

\footnotetext{
${ }^{9}$ In our descriptive tables we pool whites and Asians, though in our regression estimates below we separate them (white are the omitted group and Asians are indicated by a dummy variable). Though Asians earn more than whites, even controlling for education and achievement, their numbers are too small to generate major inconsistencies between the earlier descriptive results and our regression estimates.

${ }^{10}$ We experimented with controlling for high school GPA rather than FCAT scores. Results were qualitatively very similar. High school grade point average (GPA) more strongly predicts postsecondary education outcomes while FCAT more strongly predicts earnings. Correlations between the two measures were just above 0.7.

${ }^{11}$ For instance, Jepsen et al. (2014) uses a fixed effects estimator on a sample of college-goers with observed earnings before attending community college, comparing earnings after degree receipt to before.
} 
equations, we add measures of postsecondary achievement - such as college GPA and the number of credits earned in math or science courses - to see the extent to which such achievement is rewarded in the job market. Returns to different fields of study at different levels of higher education are estimated in separate equations as well. Finally, we separate out those achieving different types of associate degrees (such as Associate in Arts v. Applied Science, or AA v. AAS) to see the extent to which the kind of degree achieved affects subsequent labor market earnings as well.

\section{Empirical Results}

\subsection{Summary Results}

Table 1 presents our estimates of higher education and labor market outcomes for Florida students in our sample. These outcomes include quarterly earnings as well as observed high school completion rates; higher educational attainment and enrollment rates, conditional on completing high school; and higher education completion rates, conditional on enrollment. These results appear for all students and workers in part A, and then separately for race/gender groups and for FRL/gender groups respectively in parts $B$ and $C$.

The results in part A show that quarterly earnings for all workers in our sample average about $\$ 5,200$ and have considerable variation, though this estimate is likely biased by out-of-state migration of higher-achieving students and workers on the high end, and by labor force nonparticipation on the low end. ${ }^{12}$ Just over two-thirds of all students complete high school - a rate roughly consistent with computations using administrative data from other states in this period. ${ }^{13}$

\footnotetext{
${ }^{12}$ We present quarterly, rather than annualized, earnings to be consistent with previous studies (e.g., Jepsen et al., 2014). To eliminate outliers, we limited our sample of quarterly earnings between $\$ 100$ and $\$ 100,000$.

${ }^{13}$ Swanson (2004) presents high school dropout rates using administrative data, though Mishel and Roy (2006) compare them to survey-based estimates which are much higher. Using either method, Murnane (2013) shows a large decline in the estimated dropout rate over the past decade.
} 
In our sample, 11,53 , and $28 \%$ of high school graduates enroll in vocational certificate, $A A$, or BA programs, respectively. As shown in part B, both Hispanic males and females are relatively more likely to enroll in AA programs, with $64 \%$ of Hispanic females choosing to pursue an AA degree on the high end and only $43 \%$ of black males on the low end. On the other hand, white students are relatively more likely to enroll in a BA program.

The data also indicate that 4, 16 and $19 \%$ of high school graduates obtain vocational certificates, AA or BA degrees respectively in public institutions in Florida. These numbers are substantially lower than the share of students who enroll, due to low completion rates, especially for those enrolled in AA programs. Large differences in completion rates are apparent across racial/gender groups. For every 100 white male students who enroll in an AA program, about 30 will earn an associate's degree, compared to 15 for black males and 24 for Hispanic males. As shown in Table 1C, completion rates are similarly lower for FRL students relative to non-FRL students.

It should be noted that the BA attainment rate is also likely downward biased by the outmigration of higher-achieving and higher-income students in these data, as noted above; but the observed AA rates are likely much less downward-biased by these factors. The fact that completion rates are somewhat higher in vocational certificate programs than in AA programs, though overall enrollments are much lower, is notable as well.

When these rates are computed separately by race/gender and FRL/gender, we find several results, many of which have been observed elsewhere (e.g., Holzer and Dunlop, op. cit):

- Whites earn more than blacks and have higher rates of educational attainment, enrollment and completion than blacks or Hispanics;

- The poor (as measured by FRL) also have lower rates of attainment, enrollment and completion; and 
- Educational outcomes are generally higher for females in each racial or income group (Holzer and Dunlop, op cit.) though their earnings are lower.

We also note that educational attainment and labor market outcomes for Hispanics are consistently better than those for African-Americans; this partly but not entirely reflects the presence of higher-achieving and higher-earning Cubans among the latter (Borjas, 1987). However, outcomes tend to be better for non-Cuban Hispanics too. ${ }^{14}$ Higher education and labor market outcomes of those from FRL households are generally similar to, or a bit better than, those observed for blacks in Florida.

Two other outcomes are notable as well: first, males are generally more likely than females to enroll in and complete vocational programs; and second, black males lag behind black females by even more than those of other groups, and they earn only marginally more than the females in the job market. For instance, the rate of both $B A$ and $A A$ attainment for black females is more than twice as high as that of black males. While $17 \%$ of black females earn a bachelor's degree, less than $8 \%$ of black males do. The general underrepresentation of black (and/or) low-income men that we commonly find in survey data likely creates less bias in these administrative data, but perhaps some bias still exists. ${ }^{15}$

Table 2 presents some additional estimates of intermediate higher education and labor market outcomes. These include our measures of high school achievement - GPA and math FCAT - as well as somewhat similar measures of postsecondary achievement - postsecondary GPA, credits earned (among all students, whether or not they have completed their programs), and numbers of math or science credits. Intermediate outcomes for the labor market - work experience and job tenure - appear as well. Again, estimates of outcomes appear for the entire sample of students and workers in part A, and for race/gender and FRL/gender groups in parts B and C of the table respectively.

\footnotetext{
${ }^{14}$ When examining Hispanics separately by subgroup in the subsequent earnings regressions, relative to whites all Hispanic groups earned more on average. The highest earners are Cuban-born (about $\$ 1,200$ extra per quarter) and lowest earners are Puerto Rican-born (\$170 extra per quarter).

${ }^{15}$ While surveys tend to undercount low-income men, especially those who have been previously incarcerated or who are only marginally attached to households, the administrative data will undercount men or women whose employment is sporadic and informal, especially those paid in cash.
} 
The results in part A show high school and postsecondary GPAs that average about 2.2. About a fourth of all postsecondary credits earned are in math or science, and most workers have accumulated over 4 years of work experience on average, with a third of these quarters being with their current/most recent employer.

Comparing these outcomes across race/gender or FRL/gender groups generate findings similar to those in Table 1; namely, that males generally have more labor market experience or tenure than females in each group (with black students being the exception), but lower GPAs and postsecondary credits earned. Results for FCAT math scores are more mixed - with higher scores among males than females in most groups but lower scores among black males than females. Once again, minorities score lower than whites on most academic measures, and FRL students score lower than non-FRL. The average white male accumulates about 68 postsecondary credits, compared to 51 for black males and 64 for Hispanic males. In addition, Hispanics outperform blacks (and FRL) on academic measures, and even accumulate nearly as much work experience as whites. Black males lag behind their female counterparts in educational outcomes by more than we observe for other groups. For example, the average black female earns 68 postsecondary credits with a postsecondary GPA of about 2.0, while the average black male earns 51 credits with an average GPA of 1.7 .

\subsection{Selection by High School Achievement}

Undoubtedly, young people with different levels of academic achievement self-select into different higher education programs, institutions and fields of study, and differ in terms of their labor market participation and occupational choices Across groups, to what extent do differences in academic or labor market performance reflect differential selection based on students' ability and early academic achievement? 
Table 3 presents the full range of higher education and labor market outcomes observed in earlier tables, but this time they appear separately for individuals who fall into each of four quartiles (where 1 is lowest and 4 is highest) on the high school math FCAT tests.. Parts A, B, C and D of these tables reflect summary outcomes for all workers and students, then separately by gender, race, and FRL status respectively. In these tables, differences in outcomes observed between FCAT quartiles likely reflect the effects of selection by ability/achievement, while those differences within FCAT quartiles are likely attributable to other factors.

The results in Table 3A show large differences in both academic and labor market outcomes across FCAT quartiles. These differences are clearest and monotonic across achievement quartiles for earnings and tenure; BA attainment, enrollment and completion; and various measures of postsecondary achievement. In particular, BA enrollment and completion rates are heavily affected by selection on high school achievement. Enrollment in and completion of certificate and AA programs are less clearly affected by such selection.

Additionally, regardless of quartile, we find low completion rates in AA and BA programs. Specifically, conditional on enrollment, we find that $46 \%$ and $66 \%$ in the top quartile complete their AA and BA programs respectively; the comparable numbers in the second quartile are $26 \%$ and $50 \%$ respectively. These findings suggest that, at any level of achievement, a range of other factors seem to influence higher education outcomes.

These findings are generally confirmed in Tables 3B-3D, which show the results broken out by gender, race and FRL status. While differences between academic and labor market outcomes are partly accounted for by differences in high school achievement across these groups, important differences between them remain even at particular levels of achievement. For instance, we find that: 
- Women have higher postsecondary enrollments, GPA and completion rates than men within achievement quartiles, but they still earn less than men and accumulate less work experience within all but the top quartile;

- Black BA enrollments and postsecondary credits are often higher than those of whites within achievement quartiles, but their completion rates at all levels lag behind, as do their labor market earnings and attainment of work experience; and

- FRL students lag behind non-FRL students in BA enrollments (and in AA enrollments below the top quartile), all intermediate postsecondary outcomes, and in earnings.

Within achievement quartiles, differences in educational attainment are large and quantitatively important, and we need to understand their determinants much better than we presently do.

\subsection{Fields of Study}

It is well known that, for any level of academic attainment, labor market rewards differ significantly across fields of study (Altonji et al., 2012). In particular, the fields of science, technology, engineering and math (or STEM) are relatively highly rewarded. Among those completing degrees beyond the BA, the professions of law, medicine and business pay more than many of those in Ph.D. programs.

To what extent does selection into these fields of study reflect differences in earlier achievement? And to what extent are there observed differences by gender, race, or FRL status?

Some answers appear in Table 4, where we present the distributions of students across fields of study. We present these distributions separately for those in Vocational/Certificate, AA and BA programs; and, within those, separately for completers and all attempters. If we compare ratios of concentration levels of completers to attempters by field, we can infer differential completion rates across these fields at each level of schooling. As before, we present results for all students/workers in 
part A, and then separately by gender, FRL status, and high school achievement groups (bottom v. top half) in parts $B, C$, and $D$ respectively. ${ }^{16}$

Among our results, we find that vocational certificate students tend to concentrate heavily in Health Technology and Security, and to a lesser extent Construction and Other Health, and their completion rates are high in all these categories. Students at the AA level are concentrated in Legal studies and Humanities, but completion rates are quite low in the latter. At the BA level, concentrations are high in Business/Management and the Social Sciences, and to a lesser extent in Other Health, Education, Engineering, the Humanities, and Math/Physical Sciences; and completion rates are relatively low in Engineering, Math/Physical Sciences and the Humanities.

Among specific groups we find:

- Men tend to concentrate more than women in traditionally male-dominated fields (like construction and security) but also in more technical (e.g., engineering) and/or higher-paying fields (like business at the BA level and above), likely contributing to their higher earnings than women;

- FRL students concentrate more than others in Humanities at the AA and BA levels, while they (and lower performing students more generally) concentrate much less frequently in technical fields like Engineering and Math/Statistics; and

- Completion rates are a bit lower for FRL and/or lower performing students within many fields.

Overall, these results suggest that students from disadvantaged backgrounds and/or with lower academic performance sometimes sensibly avoid STEM programs, which they may have difficulty completing. On the other hand, their relatively higher concentration in other low-completion areas, like Humanities at the AA and BA levels (which is almost always "liberal arts" or "general studies" at the former), is potentially more troubling.

${ }^{16}$ Results for minority (especially black) students are similar to those for FRL students. 


\subsection{Regression Results}

Tables 5-7 show the results of estimated versions of Equation 1. The dependent variable is the natural log of quarterly earnings, and the sample is limited to those 18 years of age and older who have exited, or never entered, postsecondary education. The wage data are available for 5 years following a student's last educational enrollment. ${ }^{17}$

Five specifications of Equation 1 appear in Table 5. The first includes dummy variables for highest educational attainment, quarters of work experience and tenure with the current employer (in linear and quadratic form), high school math FCAT score (to control for academic selection effects), and demographic dummy variables (race, gender, and FRL eligibility). ${ }^{18}$ The second equation adds the number of credits earned at either a two- or four-year school for students who enrolled but did not complete a degree. The third equation allows for non-linear returns to college credits by allowing the return to vary by the number of credits earned. ${ }^{19}$ In the fourth equation, we add additional controls for postsecondary academic achievement: GPA and numbers of postsecondary courses taken in math and science. In the fifth equation, the dummy variable for AA degrees is split into those obtaining an Associate of Applied Science (AAS) or Associate of Science (AS) degree versus all others.

Several important findings appear in Table 5. As expected, we find strong labor market returns on average to all postsecondary credentials. Specifically, those obtaining a vocational certificate earn approximately 30 percent more per quarter than high school graduates; those earning AA degrees earn 35-40 percent more than high school graduates - though returns to AAS/AS degrees are much higher

\footnotetext{
${ }^{17}$ By focusing on students' earnings after their education has been completed, we avoid confounding those with periods of lower earnings before or during the attainment of postsecondary credentials.

${ }^{18}$ Missing value dummy variables for all of these measures are used in the regressions, with zeroes imputed for the missing values.

${ }^{19}$ Many community colleges in Florida offer BA degrees; however, the nature of the data make it difficult to distinguish credits earned at a community college in pursuit of a BA from credits earned at a community college in pursuit of a different degree. To ensure a clean measure of credits earned in pursuit of a BA (four-year credits), we drop the approximately 500 students who attempt a BA at a two-year institution and the 100 students who earn a BA at a two-year institution.
} 
than those for other AAs (in Column 5); and the BA degree earns $60-80$ percent more per quarter, which is about double what AA degrees earn, and those with graduate degrees earn considerably more. ${ }^{20}$

The results in the second and third equations indicate that there are also returns, on average, to attending a program and earning credits, even if the program is not completed. In addition, there are larger returns (relative to those with no postsecondary enrollment) to accumulating more credits. ${ }^{21}$ But these returns are smaller than those for completed degrees, indicating a sheepskin effect, especially for bachelor's degrees. The magnitudes are broadly consistent with others who have found evidence of these effects in the literature (e.g., Kane and Rouse, Jepsen et al., Kreisman et al., op. cit.). Furthermore, since most dropouts accumulate many fewer credits than program completers, the dropouts are relatively hurt both by their fewer credits and by the absence of the formal credential. Thus, the low levels of completion observed in AA programs, and the gaps between race, income and achievement groups at the BA level, all reduce the future earnings of minority and low-income students.

There is also a very strong return to postsecondary GPA, and also a return to taking math and science courses. When these variables are added to the equation, the estimated returns to completed degrees drop substantially, which indicates that at least some part of the observed returns to degree programs are really for overall achievement and technical skills. ${ }^{22}$ On the other hand, it could also be the case that high postsecondary GPA captures unmeasured ability in a way our other variables do not, explaining the increase in earnings. The relatively high returns to mostly technical certificate programs,

\footnotetext{
${ }^{20}$ Kane and Rouse (1995) report that a year of schooling at the two-year level is valued similarly in the labor market to one from a four-year school. But Acemoglu and Autor (2011) report a recent "convexification" of the returns to schooling, in which each year of additional postsecondary schooling generates higher average value for all.

${ }^{21}$ The relatively large returns to CC students with zero credits are puzzling to us. They might indicate some selection into these schools by unobservables not captured by our FCAT scores or other variables. In contrast, the near-zero return to those with no credits in BA programs suggests no such selection for these students.

${ }^{22}$ When postsecondary GPA and math/science credits are added separately, the former generates a much larger decline in the value of the degree than the latter. Details are available from the authors. Also, the coefficients on math/science credits in Col. 4 cannot be directly compared to the returns to credits measured there and earlier, since the latter is only for degree non-completers while the former is for all student/workers.
} 
and to AAS/AS degrees rather than AAs, confirm that the market returns to technical skills, including at the sub-BA level, are relatively large. ${ }^{23}$

A few other findings in Table 5 are noteworthy. First, the returns to general work experience are modest but in contrast, the returns to tenure are quite substantial, with a first quarter return of about eight percent. Thus, accumulating job tenure for a year or more is quite substantially rewarded. Though we made no effort here to measure returns to work experience specifically tied to one's postsecondary degree - which presumably are much greater than these - the results indicate that accumulating some kinds of work experience before, during or after one's postsecondary schooling can be valuable. In addition, the returns to FCAT indicate some significant academic selection effects, for which we control here. Other attempts to control for such selection (such as with high school GPA) generated somewhat smaller (or zero) effects, so we limited ourselves to the FCAT measure.

Finally, we note the coefficients on demographic variables in these equations. Interestingly, controlling for the full range of academic attainment and achievement generates even larger negative effects for females - of 15 percent per quarter - than we found in Table 1, since their achievement measures are generally higher than those of males while their earnings are lower. Controls for education and achievement also generate large (15 percent) returns for Hispanics relative to whites. And, for blacks and low-income students, estimated negative effects are now much smaller (6 to 12 percent per quarter) than we observed in Table 1, indicating that much (though not all) of their lower earnings is associated with lower academic attainment and achievement. ${ }^{24}$

\footnotetext{
${ }^{23}$ See the Economic and Statistics Administration (2011) for recent evidence on the labor market values of STEM jobs, and Jacobson et al. (2005) for earlier evidence on the values of community college education with more technical courses and curricula relative to those with less, though for a sample of older displaced workers.

${ }^{24}$ Johnson and Neal (1998) and Holzer and Dunlop (op. cit) show that racial gaps in earnings grow much smaller when we control for differences in education plus academic achievement. But the inclusion of quarters with zero earnings can strongly reduce the extent to which education and achievement account for the earnings gaps of black relative to white men.
} 
Despite our extensive controls for demographic information and achievement in high school, it is still possible that our estimates reflect selection on unobserved factors. For instance, for two students with the same demographic information and performance in high school who choose two different postsecondary paths and have different labor market outcomes, we cannot say for certain whether it was the paths that caused the disparate outcomes or some unobserved factor such as motivation or guidance from others. Thus, while our results are suggestive of large differences in outcomes across postsecondary pathways, they are not necessarily causal effects.

\subsection{Specific Fields, Specific Groups}

To further explore how these average effects on earnings vary with field of study, we present returns to different fields in Table 6. These estimates are from versions of Equation 1 containing dummy variables for fields of study, with Humanities as the omitted group. In separately estimated equations, we present results for those earning AAs or certificates versus those earnings BAs.

The results show substantial variation in returns across fields of study. In particular:

- Those earning sub-BA credentials have relatively strong returns to health, transportation, construction, manufacturing (mostly certificates), and security credentials; and

- For those earning BAs or higher, returns are strongest in transportation, engineering, and business management and health, with smaller but still positive pay premia (relative to humanities) in the math/science, communications, legal work, and health technology. ${ }^{25}$

Importantly, the returns to the omitted category of AAs, humanities - the most commonly pursued degree in two-year colleges and also a field with relatively low completion rates - are relatively low, compared to virtually all other fields. A strong case can be made therefore the large concentrations

\footnotetext{
${ }^{25}$ We find similar patterns across fields of study among those not completing degree programs, although the results are not quite as pronounced. Results are available from the authors.
} 
of AA students - especially among disadvantaged students - in these low completion and low return areas is sub-optimal in terms of future earnings potential.

Our final research question is how these market returns vary across different demographic groups of students, or those with higher or lower overall levels of earlier achievement. To answer this question we estimate the model (also based on the first equation in Table 5) separately for males and

females, for those eligible or not eligible for FRL and for those in the top or bottom half of FCAT scores. ${ }^{26}$ These estimates appear in Table 7.

Overall, the patterns of market returns to postsecondary attainment and achievement are quite similar across demographic and achievement groups. A few modest differences can be found. For instance:

- Men earn relatively larger rewards than women, both in certificate programs and BAs and above, while women do better in AA programs;

- Academic credentials, including vocational certificates and AAs, are also relatively wellrewarded for FRL students and those students in the bottom half of high school achievers.

Thus, labor market rewards are broadly similar across these groups. But, in some more technical fields, achieving a vocational certificate or even an AA can be quite rewarding, especially among lowerachieving groups, and particularly if they can combine these credentials with good work experience or tenure afterwards.

\section{Conclusion}

Our paper examines a range of issues focusing on postsecondary education and labor market outcomes, with a particular focus on minorities and/or disadvantaged workers. We use administrative data from the state of Florida, where secondary and postsecondary education records for two cohorts of

\footnotetext{
${ }^{26}$ We have estimated separate equations by race as well as FRL. Findings are similar and available from the authors.
} 
students have been linked to UI earnings data (for five years after schooling has been completed). The administrative data give us enormous samples with which to study particular groups of students, with very detailed information on educational experiences and outcomes for every public school student in a particular year. In addition, the secondary education records to which we have access enable us to test and control for selection based on early academic experience and achievement, to a much greater extent than has been the case with other studies using administrative data. However, the data have their limitations, for instance, we cannot follow those who leave Florida to attend college or enter the labor force elsewhere. Yet, the richness of the data on educational experiences and outcomes, coupled with the recentness of the cohort and our large sample size enable us to learn a great deal about postsecondary outcomes and their determinants.

Our main findings can be summarized as follows:

1) Variation in secondary school achievement can account for a large part of the gap in postsecondary attainment (through the differences we observe in enrollment rates and especially in completion) and labor market outcomes between racial and family income groups, but quite large differences also exist within achievement groups;

2) Earnings of minorities and disadvantaged students are reduced not only by their lower educational attainment and completion but also by weaker postsecondary academic performance and by their chosen fields of study.

More specifically, significant labor market premia are available in a variety of more technical certificate and AA programs, even for those with weak earlier academic performance. However, many disadvantaged (and other) students end up in general humanities (or liberal studies) programs at the AA (and even the BA) level with low completion rates and low compensation afterwards.

Of course, students in liberal arts curricula, and especially those planning on post-BA education, are not necessary harmed by majoring in humanities. And in none of this work can we control for 
students' preferences across fields, and therefore we cannot infer whether these outcomes reflect suboptimal choices on the part of students.

On the other hand, it is likely that many students in AA programs, especially disadvantaged students or those with weaker academic performance, do not plan on obtaining post-BA education and are hoping that their college experiences lead directly to higher earnings. For these students, the very high concentrations we observe in humanities programs at the AA level do not appear consistent with those goals.

One can imagine a variety of reallocations of students from these programs that would improve expected student outcomes, especially among the disadvantaged. These reallocations might include moving the higher achievers in this group to BA programs (especially at more selective institutions, where completion rates are relatively high) or to more technical AA fields of study with higher completion rates and earnings; while lower achievers might do better in some of the well-compensated vocational certificate programs. Additionally, certificate programs and work experience are particularly well-compensated among young men, especially African-American men who have difficulty gaining work experience and whose postsecondary attainments also lag substantially behind those of women.

How might such reallocations be accomplished? Poor choices by postsecondary students likely reflect at least two problems: poor information among students and poor incentives faced by their postsecondary institutions. Due to an unstructured environment and poor counseling, students in community college receive very little information about either academic or job market opportunities. Improving the guidance provided to these students would likely improve their outcomes (Scott-Clayton, 2011; Jenkins and Cho, 2012; Rosenbaum et al., 2006; Jacobson and Mokher, 2009). But public institutions also need more incentive to respond to labor market factors, and prepare students for wellpaying or higher-demand fields, even if the costs to them of instruction and equipment in these fields are higher (Holzer, 2014). Incentivizing these institutions to build more partnerships with industry 
associations, generating sectorial and career pathway programs, and helping students participate in them could be accomplished by greater use of postsecondary and earnings performance measures in determining state subsidies for public colleges and universities. ${ }^{27}$

In addition to these approaches, a few other broad policy guidelines are at least consistent with, and are perhaps suggested by, our findings. In particular, disadvantaged students would benefit from reforms in support programs and services, such as developmental education and financial aid. Students might also benefit from work-based learning models and other pathways to postsecondary education, such as apprenticeships and other forms of high-quality career education, which do not substitute work experience for postsecondary learning but complement it and lead to improved labor market outcomes. ${ }^{28}$ Experimentation with, and further evaluation of reforms in these support services and alternative pathways to skill creation should be a high priority.

\footnotetext{
${ }^{27}$ The National Governors Association (2013) reports a widespread attempt to build "sectorial" training partnerships at the state and regional levels between community colleges and industry groups, though we have little data on the scale of student enrollments in programs generated through these partnerships. The National Council of State Legislatures (2014) reports that over half of all states are planning to at least partially use higher education academic outcomes to determine state subsidies to higher education institutions, and Holzer (2014) argues that employment outcomes should also be used to measure institutional performance as well. But the use of such outcomes without adjusting for the quality of student inputs could result in "creaming-skimming" through higher admissions standards, among other potential unanticipated consequences.

${ }^{28}$ Models of high-quality career and technical education, such as apprenticeship, increasingly build the attainment of postsecondary credentials like AA degrees into their training model. See Lerman (2010).
} 


\section{References}

Acemoglu, Daron and David Autor. 2011. "Skills, Tasks and Technologies: Implications for Employment and Earnings." In O. Ashenfelter and D. Card eds. The Handbook of Labor Economics, Vol. 4. Amsterdam: North Holland.

Altonji, Joseph et al. 2012. "Heterogeneity in Human Capital Investments: High School Curriculum, College Major, and Careers," National Bureau of Economic Research Working Paper.

Bailey, Martha and Susan Dynarski. 2011."Inequality in Postsecondary Education." In G. Duncan and R. Murnane eds. Whither Opportunity? Rising Inequality, Schools, and Children's Life Chances. New York: Russell Sage Foundation.

Borjas, George. 19897. "Self-Selection and the Earnings of Immigrants." American Economic Review. Vol. 77, No. 4, 531-53.

Bound, John et al. 2009. "Why Have College Completion Rates Declined? An Analysis of Changes in Student Preparation and College Resources." National Bureau of Economic Research Working Paper.

Economic and Statistics Administration. 2011. STEM: Good Jobs Now and For the Future. US Department of Commerce.

Haskins, Ron et al. 2009. Promoting Economic Mobility by Increasing Postsecondary Education. The Pew Trusts, Washington DC.

Holzer, Harry. 2014. "Improving Employment Outcomes for Disadvantaged Students." Hamilton Project, The Brookings Institution, Washington DC.

Holzer, Harry and Erin Dunlop. 2013. "Just the Facts, Ma'am: Postsecondary Education and Labor Market Outcomes in the U.S." CALDER Working Paper, American Institutes for Research, Washington DC.

Hoxby, Caroline and Susan Turner. 2013. Informing Students About their College Prospects: A Proposal for Broadening the Expanding College Opportunity Project. The Hamilton Project, Brookings Institution, Washington DC.

Institute of Education Sciences. 2014. Digest of Education Statistics. U.S. Government Printing Office. Washington DC.

Isaacs, Julia. 2007. Economic Mobility of Families across Generations. Policy Brief, Center on Children and Families, the Brookings Institution.

Jacobson, Louis and Christine Mokher. 2009. Pathways to Boosting the Earnings of Low-Income Students by Increasing their Educational Attainment. Hudson Institute, New York.

Jacobson, Louis et al. 2005. "The Impact of Community College on Older Workers: Should We Teach Old Dogs New Tricks?” Working Paper, Cornell ILR School. 
Jenkins, Davis and Sung-Woo Cho. 2012. "Get with the Program: Accelerating Community College Entry Into and Completion of Programs of Study." Community College Research Center Working Paper, Teachers College, Columbia University.

Jepsen, Christopher, Kenneth Troske, and Paul Coomes. 2014. "The Labor-Market Returns to Community College Degrees, Diplomas, and Certificates," Journal of Labor Economics, University of Chicago Press, vol. 32(1), pages 95 - 121.

Johnson, William and Derek Neal. 1998. "Basic Skills and the Black-White Earnings Gap." In C. Jencks and M. Phillips eds. The Black-White Test Score Gap. Brookings Institution, Washington DC.

Kane, Thomas and Cecelia Rouse. 1998. "The Labor Market Returns to Two-and Four-Year Colleges." American Economic Review. Vol. 85, No. 2, 600-14.

Kreisman, Daniel et al. 2013. "The Returns to Couse Credits, Certificates and Degrees: Evidence from Michigan's Community Colleges." Unpublished, University of Michigan.

Lerman, Robert. 2010. "Expanding Apprenticeships: A Way To Improve Skills and Careers." The Urban Institute, Washington DC.

Lovenheim, Michael and Curtis Reynolds. 2011. "Changes in Postsecondary Choices by Ability and Income: Evidence from the National Longitudinal Surveys of Youth." Journal of Human Capital, vol. 5(1), 70-109.

Malamud, Ofer and Abigail Wozniak. 2008. "The Impact of College Graduation on Geographic Mobility: Identifying Education Using Multiple Components of Vietnam Draft Risk." IZA Discussion Paper Series No. 3432.

Mishel, Lawrence and Joydeep Roy. 2004. Rethinking High School Graduation Rates and Trends. Economic Policy Institute, Washington DC.

Murnane, Richard. 2013. "U.S. High School Graduation Rates: Patterns and Explanations." Journal of Economic Literature. Vol. 51, No. 2, 370-422.

National Council of State Legislatures. 2014. "Performance-Based Subsidies for Higher Education." http://www.ncsl.org/research/education/performance-funding.aspx

National Governors' Association. 2013. State Sector Strategies Coming of Age. Center for Best Practices, Washington DC.

Reardon, Sean. 2011.The Widening Academic Achievement Gap Between the Rich and the Poor: New Evidence and Possible Explanations." In G. Duncan and R. Murnane eds. Whither Opportunity? Rising Inequality, Schools, and Children's Life Chances. New York: Russell Sage Foundation.

Rosenbaum, James et al. 2006. After Admission: From College Access to College Success. New York: Russell Sage Foundation. 
Scott-Clayton, Judith. 2011. "The Shapeless River: Does a Lack of Structure Inhibit Students' Progress at Community Colleges?" Community College Research Center Working Paper, Teachers College, Columbia University.

Swanson, Christopher. 2004. Who Graduates? Who Doesn't? A Statistical Portrait of Public High School Graduation, Class of 2001. Washington, D.C., The Urban Institute. 


\section{Tables}

\section{Table 1 - Education and Labor Market Outcomes: Summary Statistics}

\section{A. All Students and Workers}

$\begin{array}{lc}\text { Quarterly Earnings } & \$ 5,227.36 \\ \text { N } & (4572.22) \\ \text { Educational } & 3,975,013 \\ \text { Attainment } & \\ \text { HS } & \\ \text { Voc/Cert } & 0.693 \\ \text { AA } & 0.044 \\ \text { BA or above } & 0.159 \\ \text { N } & 0.193 \\ \text { Enrollment } & 393,213 \\ \text { Voc/Cert } & \\ \text { AA } & 0.106 \\ \text { BA } & 0.529 \\ \text { Completion } & 0.283 \\ \text { Voc/Cert } & \\ \text { AA } & 0.419 \\ \text { BA } & 0.300 \\ & 0.592\end{array}$

Notes: Quarterly earning observations are labor market quarters while educational outcomes are calculated out of unique students. Standard deviations for continuous variables are in parentheses below their corresponding means. All postsecondary attainment and enrollment are conditional upon HS graduation. Completion for a degree level is conditional upon enrollment in that degree. 
Table 1 (cont'd)

\section{B. By Race/Gender}

\begin{tabular}{lcccccc} 
& \multicolumn{2}{c}{ White } & \multicolumn{2}{c}{ Black } & \multicolumn{2}{c}{ Hispanic } \\
& Male & Female & Male & Female & Male & Female \\
Quarterly Earnings & $\$ 5,746.43$ & $5,245.16$ & $4,237.60$ & $4,140.88$ & $5,654.21$ & $5,473.62$ \\
& $(4967.67)$ & $(4575.25)$ & $(3779.69)$ & $(3625.38)$ & $(4638.84)$ & $(4332.01)$ \\
N & $1,243,071$ & 906,996 & 528,548 & 463,994 & 415,221 & 320,809 \\
Educational & & & & & & \\
Attainment & & & & & & \\
$\quad$ HS & 0.716 & 0.774 & 0.531 & 0.664 & 0.619 & 0.700 \\
$\quad$ Voc/Cert & 0.063 & 0.037 & 0.034 & 0.040 & 0.048 & 0.025 \\
$\quad$ AA & 0.137 & 0.209 & 0.066 & 0.132 & 0.135 & 0.206 \\
$\quad$ BA or above & 0.168 & 0.266 & 0.075 & 0.170 & 0.125 & 0.217 \\
Enrollment & & & & & & \\
$\quad$ Voc/Cert & 0.113 & 0.082 & 0.121 & 0.147 & 0.116 & 0.085 \\
$\quad$ AA & 0.459 & 0.561 & 0.433 & 0.594 & 0.556 & 0.640 \\
$\quad$ BA & 0.255 & 0.347 & 0.157 & 0.265 & 0.224 & 0.322 \\
Completion & & & & & & \\
$\quad$ Voc/Cert & 0.555 & 0.445 & 0.281 & 0.274 & 0.414 & 0.289 \\
$\quad$ AA & 0.299 & 0.373 & 0.153 & 0.222 & 0.243 & 0.322 \\
BA & 0.580 & 0.658 & 0.422 & 0.549 & 0.494 & 0.573
\end{tabular}




\section{Table 1 (cont'd)}

\section{By FRL/Gender}

Non-FRL

\section{FRL}

Male Female Male Female

Quarterly earnings

$\$ 5,943.05 \quad 5,610.97 \quad 4,740.15 \quad 4,236.17$

$\begin{array}{lllll}(5138.77) & (4755.39) & (3965.59) & (3555.97)\end{array}$

$\mathrm{N}$

$1,241,573 \quad 968,371 \quad 865,102 \quad 698,666$

\section{Educational}

Attainment

HS

Voc/Cert

AA

0.744

0.812

0.589

0.671

0.059

0.035

0.044

0.037

0.145

0.217

0.087

0.147

BA or above

0.187

0.295

0.065

0.126

Enrollment

Voc/Cert

0.113

0.085

0.118

0.120

AA

0.501

0.590

0.448

0.588

BA

0.288

0.389

0.139

0.211

\section{Completion}

Voc/Cert

AA

0.521

0.408

0.377

0.310

BA

0.290

0.368

0.194

0.249

0.572

0.648

0.421

0.519 
Table 2 - Intermediate Education and Labor Market Outcomes: Summary Statistics

\section{A. All Students/Workers}

Intermediate HS Outcomes

10th grade FCAT math score $\quad 0.000$

$\begin{array}{lc} & (1.000) \\ \text { HS GPA } & 2.208\end{array}$

Intermediate Postsecondary Outcomes

$\begin{array}{ll}\text { Postsecondary GPA } & 2.271\end{array}$

Total Postsecondary Credits

(61.321)

Postsecondary Math Credits $\quad 7.730$

Postsecondary Science Credits $\quad$ (8.207)

Postsecondary Science Credits $\quad 11.016$

Labor Market Inputs

Work Experience $\quad 18.886$

$(11.272)$

Tenure $\quad 6.206$

(6.897)

Note: Intermediate HS and postsecondary outcomes are calculated out of numbers of unique students, while labor market inputs are calculated out of labor market quarters. 
Table 2 (cont'd)

\section{B. By Race/Gender}

Intermediate HS Outcomes

White

Male Female Male Female Male Female

10th grade FCAT Math Score

HS GPA

$\begin{array}{cccccc}0.287 & 0.264 & -0.691 & -0.561 & -0.149 & -0.175 \\ (0.922) & (0.822) & (1.074) & (0.966) & (1.006) & (0.913) \\ 2.188 & 2.533 & 1.804 & 2.087 & 1.945 & 2.263 \\ (0.994) & (0.972) & (0.891) & (0.912) & (0.920) & (0.912)\end{array}$

Intermediate Postsecondary Outcomes

$\begin{array}{lcccccc}\text { Postsecondary GPA } & 2.266 & 2.568 & 1.718 & 1.967 & 2.062 & 2.301 \\ & (1.102) & (0.995) & (1.103) & (1.048) & (1.089) & (1.013) \\ \text { Total Postsecondary Credits } & 68.515 & 79.069 & 50.597 & 68.157 & 63.976 & 77.191 \\ & (60.08) & (60.723) & (57.608) & (63.531) & (58.351) & (60.534) \\ \text { Postsecondary Math Credits } & 7.657 & 7.732 & 6.055 & 7.347 & 8.261 & 8.800 \\ & (8.682) & (7.189) & (8.573) & (8.062) & (9.153) & (8.104) \\ \text { Postsecondary Science Credits } & 9.331 & 12.999 & 6.53 & 11.4 & 8.518 & 12.219 \\ & (15.527) & (18.504) & (13.53) & (18.211) & (14.853) & (18.246)\end{array}$

\section{Labor Market Inputs}

Work Experience

$\begin{array}{cccccc}19.451 & 19.12 & 17.703 & 18.401 & 19.027 & 18.955 \\ (11.397) & (10.881) & (11.567) & (11.214) & (11.536) & (11.109) \\ 6.500 & 6.357 & 5.616 & 5.723 & 6.174 & 6.421 \\ (7.274) & (6.794) & (6.696) & (6.437) & (6.882) & (6.747)\end{array}$


Table 2 (cont'd)

\section{By FRL/Gender}

\section{Intermediate HS Outcomes}

Non-FRL FRL

$\begin{array}{lcccc}\text { 10th grade FCAT math score } & 0.242 & 0.220 & -0.381 & -0.398 \\ & (0.954) & (0.856) & (1.035) & (0.928) \\ \text { HS GPA } & 2.286 & 2.628 & 1.805 & 2.088 \\ & (0.936) & (0.901) & (0.909) & (0.931)\end{array}$

Intermediate Postsecondary Outcomes

Postsecondary GPA

$\begin{array}{llll}2.240 & 2.531 & 1.877 & 2.072\end{array}$

$\begin{array}{llll}(1.075) & (0.970) & (1.153) & (1.090)\end{array}$

Total Postsecondary Credits

$\begin{array}{llll}71.219 & 83.558 & 50.689 & 62.575\end{array}$

$\begin{array}{llll}(61.049) & (61.769) & (54.998) & (59.091)\end{array}$

Postsecondary Math Credits

$\begin{array}{lllll}8.097 & 8.253 & 6.496 & 7.266\end{array}$

$\begin{array}{llll}(8.926) & (7.509) & (8.692) & (7.932)\end{array}$

Postsecondary Science Credits

$\begin{array}{llll}9.927 & 14.052 & 6.620 & 10.037\end{array}$

$\begin{array}{llll}(16.161) & \text { (19.571) } & (13.549) & \text { (16.577) }\end{array}$

\section{Labor Market Inputs}

Work Experience

$\begin{array}{cccc}19.388 & 19.381 & 18.432 & 18.34 \\ (11.475) & (10.941) & (11.441) & (11.089) \\ 6.536 & 6.438 & 5.757 & 5.843 \\ (7.256) & (6.782) & (6.661) & (6.509)\end{array}$

Tenure 
Table 3 - Education and Labor Market Outcomes: by HS Achievement Quartile

\section{A. All Students/Workers}

\section{Quarterly Earnings}

Educational Attainment

Voc/Cert

AA

BA or above

Enrollment

Voc/Cert

AA

BA

Completion

Voc/Cert

AA

BA

Intermediate HS Outcomes

10th grade FCAT Math Score

HS GPA

$\begin{array}{cccc}\text { Quartile } & \text { Quartile } & \text { Quartile } & \text { Quartile } \\ \mathbf{1} & \mathbf{2} & \mathbf{3} & \mathbf{4} \\ \$ 4,383.75 & 5,227.19 & 6,159.69 & 8,072.06 \\ (3411.79) & (3955.62) & (4765.38) & (6445.16)\end{array}$

$\begin{array}{llll}0.045 & 0.054 & 0.054 & 0.035 \\ 0.082 & 0.154 & 0.220 & 0.224 \\ 0.041 & 0.104 & 0.226 & 0.453\end{array}$

0.143

0.119

0.100

0.060

0.536

0.590

0.600

0.484

0.089

0.190

0.351

0.580

$\begin{array}{llll}0.317 & 0.456 & 0.542 & 0.585 \\ 0.153 & 0.261 & 0.367 & 0.462 \\ 0.425 & 0.500 & 0.577 & 0.656\end{array}$

$\begin{array}{cccc}-1.286 & -0.194 & 0.368 & 1.131 \\ (0.823) & (0.170) & (0.166) & (0.404) \\ 1.977 & 2.342 & 2.680 & 3.159 \\ (0.679) & (0.647) & (0.640) & (0.588)\end{array}$

Intermediate Postsecondary Outcomes

Postsecondary GPA

1.734

2.120

2.427

2.841

(1.085)

$(0.995)$

$(0.930)$

(0.810)

Total Postsecondary Credits

43.542

62.603

80.698

101.912

(49.200)

(56.430)

(59.703)

(61.394)

Postsecondary Math Credits

5.401

7.957

8.893

9.481

(7.706)

(8.079)

(7.736)

(8.558)

Postsecondary Science Credits

5.476

8.908

12.638

17.412

(10.805)

(14.077)

(17.949)

(22.212)

Labor Market Inputs

Work Experience

$$
18.997
$$

19.323

19.486

18.843

(11.453)

(11.063)

(10.758)

(10.032)

Tenure

6.619

6.778

6.831

(6.944)

(7.126)

(7.002)

(6.669)

Notes: Quartile 1 is the lowest achievement level, and quartile 4 is the highest achievement level. Educational attainment and enrollment are conditional upon HS completion, and completion is conditional upon enrollment in that degree. 
Table 3 (cont'd)

\section{B. By Gender}

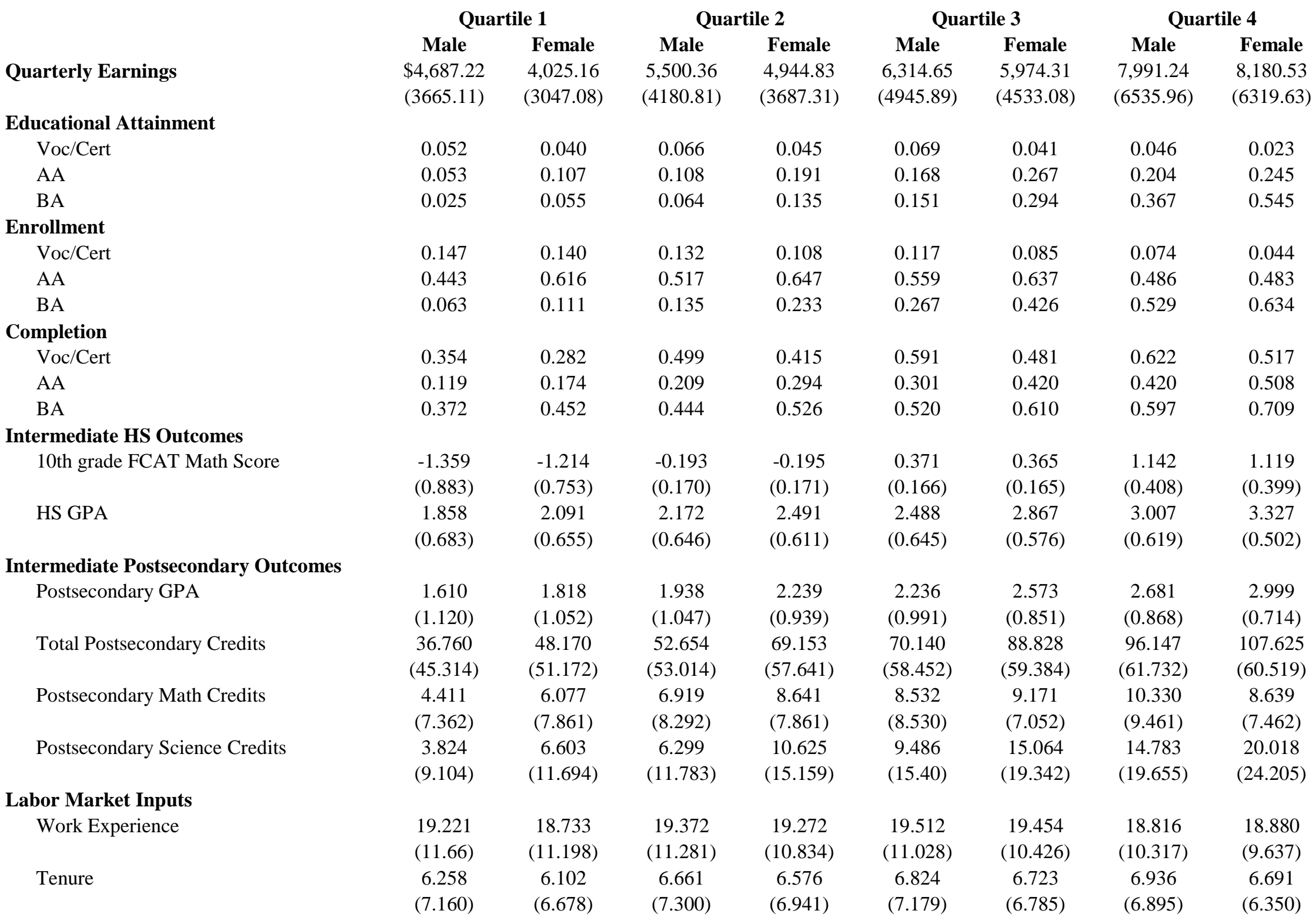


Table 3 (cont'd)

\section{By Race}

\section{Quarterly Earnings}

\section{Educational Attainment}

Voc/Cert

AA

BA

Enrollment

Voc/Cert

AA

BA

Completion

Voc/Cert

AA

BA

Intermediate HS Outcomes

HS GPA

\section{Intermediate Postsecondary Outcome}

Postsecondary GPA

Total Postsecondary Credits

Postsecondary Math Credits

Postsecondary Science Credits

Labor Market Inputs

Work Experience

Tenure

\begin{tabular}{cccccccccccc} 
& Quartile 1 & & \multicolumn{3}{c}{ Quartile 2 } & \multicolumn{3}{c}{ Quartile 3 } & Quartile 4 \\
White & Black & Hispanic & White & Black & Hispanic & White & Black & Hispanic & White & Black & Hispanic \\
$\$ 4,455.57$ & $4,036.84$ & $4,987.81$ & $5,190.27$ & $4,823.83$ & $5,791.99$ & $6,085.60$ & $5,687.52$ & $6,711.49$ & $7,934.70$ & $7,793.08$ & $8,626.83$ \\
$(3528.71)$ & $(3187.7)$ & $(3553.55)$ & $(3967.44)$ & $(3684.96)$ & $(4138.44)$ & $(4703.92)$ & $(4516.54)$ & $(4982.39)$ & $(6312.65)$ & $(6599.3)$ & $(6615.71)$
\end{tabular}

0.069

0.041

0.032

0.063

0.047

0.133

0.045

0.049

0.084

0.133

$\begin{array}{lll}0.135 & 0.159 & 0.120\end{array}$

0.127

0.118

0.442

0.559

0.629

0.556

0.582

0.398

$\begin{array}{lll}0.432 & 0.260 & 0.268\end{array}$

0.499

0.267

0.398

0.155

0.134

0.188

0.228

$\begin{array}{lll}-1.175 & -1.385 & -1.260\end{array}$

$(0.762)$

1.998

(0.869)

1.962

(0.796)

$-0.181$

(0.169)

$-0.217$

(0.17)

2.364
$(0.617)$

1.849

(1.142)

1.646

(0.668)

(0.665)

1.999

(0.936)

69.716

$\begin{array}{lll}(44.219) & (50.849) \quad(51.569)\end{array}$

4.701

5.302

6.586

$\begin{array}{lll}(6.97) & (7.739) \quad(8.468)\end{array}$

$\begin{array}{lll}4.585 & 5.752 & 5.992\end{array}$

(9.041)

(11.297)

(11.547)

$\begin{array}{lll}19.681 & 18.525 & 18.973\end{array}$

$\begin{array}{lll}(11.565) \quad(11.373) \quad(11.43) & 0\end{array}$

$\begin{array}{ccc}6.417 & 5.968 & 6.286 \\ (7.292) & (6.736) & (6.793)\end{array}$
2.179

56.596

(52.473)

7.144

(7.556)

7.692

(12.14)

19.707

(11.138)

6.867

(7.445)
(61.426)

8.458

(8.321)

10.674

(16.431)

18.560

(10.843)

6.061

(6.529)
0.042

0.186

0.109
0.186

0.102

0.674

0.210

0.411

0.276

0.464

$-0.199$

(0.171)

2.308

(0.637)

2.120

\subsection{1}

0.226

0.207

0.105

0.598

0.314

0.578

0.378

0.595

0.377

(0.165)

2.688

(0.654)

2.463

(0.981)

65.880

(56.218)

9.052

(8.657)

8.908

(13.651)

19.439

(11.129)

6.692

(6.989)

76.475

8.312

(7.341)

11.485

19.804

(10.826)

6.970

(7.212)
$0.038 \quad 0.044$

0.280

0.093

0.542

0.444

0.410

0.298

0.550

0.333

(0.163)

2.696

(0.601)

2.261

(0.890)

91.804

(16.444)

9.727

(8.491)

15.867
(20.978)

18.407

(10.495)

(6.312)
$0.162-0.237$
0.240

\subsection{9}

0.644

0.386

0.499

0.368

0.549

0.358

(0.165)

2.616

(0.618)

2.423

(0.911)

84.474

(59.144)

10.021

(8.068)

12.958

19.277

$(10.672)$

6.672

(6.679)
0.038

0.232
0.446

0.020

0.166

0.470

0.029

0.211

0.444

$\begin{array}{lll}0.063 & 0.047 & 0.054\end{array}$

$0.494-0.413$

$\begin{array}{lll}0.566 & 0.637 & 0.600\end{array}$

$\begin{array}{lll}0.603 & 0.423 & 0.535\end{array}$

$\begin{array}{lll}0.469 & 0.402 & 0.439\end{array}$

1.141

$(0.409)$

1.015

(0.305)

1.081

3.176

3.046

$(0.349)$

3.052

$2.857-2.653$

$\begin{array}{lll}2.857 & 2.653 & 2.788\end{array}$

$\begin{array}{lll}(0.816) & (0.786) & (0.792)\end{array}$

$100.025 \quad 114.108 \quad 102.806$

$(60.809) \quad(66.257) \quad(59.791)$

$\begin{array}{lll}(8.337) \quad(9.398) & (8.614)\end{array}$

$16.469 \quad 21.914 \quad 18.003$

$19.163 \quad 17.461 \quad 18.082$

$\begin{array}{lll}(10.084) \quad(9.767) & (9.833)\end{array}$

$\begin{array}{lll}6.952 & 6.044 & 6.550\end{array}$

(6.797)

(5.927)

(6.257) $\begin{array}{lll}0.665 & 0.590 & 0.622\end{array}$

$(21.238) \quad(26.452) \quad(22.569)$ 


\section{Table 3 (cont'd)}

\section{Quarterly Earnings}

\section{Educational Attainment} Voc/Cert

AA

BA

Enrollment

Voc/Cert

AA

BA

Completion

Voc/Cert

AA

BA

Intermediate HS Outcomes

10th grade FCAT math score

HS GPA

Intermediate Postsecondary Outcomes

Postsecondary GPA

Total Postsecondary Credits

Postsecondary Math Credits

Postsecondary Science Credits

\section{Labor Market Input}

Work Experience

Tenure
D. By FRL status

Quartile 1

$5,487.59$

(3608.34)

$4,220.75$

(3664.24)

Quartile 3

non-FRL

FRL

(4917.97) (4359.39)

non-FRL

$8,350.22$

(3262.46)

(4).

0.092

0.039

0.059

0.172

0.120

0.046

0.126

0.078

0.057

0.237

0.249

0.047

0.175

0.162

(6593.75)

(5459.76)

$\begin{array}{ll}0.144 & 0.144 \\ 0.552 & 0.536 \\ 0.100 & 0.082 \\ & \\ 0.372 & 0.273 \\ 0.167 & 0.140 \\ 0.457 & 0.387\end{array}$

0.122

0.610

0.209

0.113

0.556

0.102

0.614

0.095

0.559

0.284

0.034

0.226

0.480

0.039

0.212

0.300

(0.662)

$(1.070)$

$$
\begin{gathered}
1.657 \\
(1.084)
\end{gathered}
$$

(49.98)

(48.566)

$5.686 \quad 5.225$

$5.847 \quad 5.214$

(13.896)

0.057

0.479

0.073

0.601

0.521

(11.001) (10.675)

$\begin{array}{cc}19.562 & 18.636 \\ (11.556) & (11.36) \\ 6.442 & 5.986 \\ (7.188) & (6.715)\end{array}$

19.676
$(11.118)$
6.915

0.484

0.281

0.528

0.408

0.226

0.440

0.557

0.386

0.499

0.313

0.509

$-0.208$

(0.171)

2.283

(0.649)

0.376

(0.166)

2.730

(0.624)

0.348

(0.163)

2.579

(0.655)

.

2.174

2.022

(1.013)

2.461

(0.913)

82.596

2.317

(0.973)

75.059

(60.512)

(56.496)

$(56.072)$

8.102

7.714

(59.317)

8.885

(7.529)

9.162

(8.244)

8.472

12.863

(14.353)

(17.937)

(8.367)

12.042

(18.004)

18.873

19.778

6.251

7.021

(7.177)

0.595

0.472

0.669

0.538

0.407

0.553

$1.148 \quad 1.035$

(0.413) (0.333)

$3.201 \quad 2.973$

(0.569) (0.637)

$2.865 \quad 2.682$

(0.793) (0.892)

$103.629 \quad 91.618$

(60.924) (62.933)

$9.461 \quad 9.694$

(8.551) (8.631)

$17.580 \quad 16.601$

(22.205) (22.442)

(7.387)

(6.775)

18.910

18.505

(9.978) (10.317)

6.886

(6.687)

6.566

(6.603) 
Table 4 - Fields of Study

\section{A. All Students/Workers}

Fields of Study

Manufacturing

Construction

Health Tech

Other Health

Transportation

Business/Management

Education

Engineering

Communications

Legal

Security

Bio, Math/Stats, Physical

Science

Social Science

Humanities

Other

Missing

$\mathrm{N}$
Voc/Cert

Comp. Attempt

$0.007 \quad 0.009$

$0.085 \quad 0.073$

$0.258 \quad 0.130$

$0.100 \quad 0.066$

$0.004 \quad 0.004$

$0.055 \quad 0.044$

0.013

0.045

0.005

0.001

0.332

$0.005 \quad 0.004$

$0.000 \quad 0.001$

0.009

0.078

0.002

12,060
AA

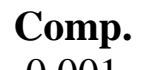

0.001

0.001

0.024

0.055

0.002

0.008

0.003

0.018

0.003

0.392

0.007

0.002

0.001

0.480

0.003

0.001

43,236
BA

Attempt Comp. Attempt

$\begin{array}{lll}0.001 & 0.000 & 0.000\end{array}$

$\begin{array}{lll}0.005 & 0.000 & 0.000\end{array}$

$\begin{array}{lll}0.023 & 0.000 & 0.001\end{array}$

$\begin{array}{lll}0.072 & 0.078 & 0.068\end{array}$

$\begin{array}{lll}0.001 & 0.000 & 0.000\end{array}$

$\begin{array}{lll}0.025 & 0.216 & 0.192\end{array}$

$\begin{array}{lll}0.007 & 0.085 & 0.080\end{array}$

$\begin{array}{lll}0.028 & 0.079 & 0.084\end{array}$

$\begin{array}{lll}0.004 & 0.060 & 0.050\end{array}$

$\begin{array}{lll}0.122 & 0.006 & 0.005\end{array}$

$\begin{array}{lll}0.016 & 0.042 \quad 0.038\end{array}$

$\begin{array}{lll}0.003 & 0.069 & 0.078\end{array}$

$\begin{array}{lll}0.003 & 0.203 & 0.180\end{array}$

$\begin{array}{lll}0.554 & 0.122 & 0.124\end{array}$

$\begin{array}{lll}0.006 & 0.034 & 0.030\end{array}$

$\begin{array}{lll}0.131 & 0.006 & 0.072\end{array}$

$144,231 \quad 45,564 \quad 77,028$

Notes: "Comp." denotes completers and "Attempt" denotes all attempters of that degree, regardless of completion status. 
Table 4 (cont'd)

\section{B. By Gender}

\begin{tabular}{|c|c|c|c|c|c|c|c|c|c|c|c|c|}
\hline \multirow[b]{3}{*}{ Fields of Study } & \multicolumn{4}{|c|}{ Voc/Cert } & \multicolumn{4}{|c|}{$\mathbf{A A}$} & \multicolumn{4}{|c|}{ BA } \\
\hline & \multicolumn{2}{|c|}{ Male } & \multicolumn{2}{|c|}{ Female } & \multicolumn{2}{|c|}{ Male } & \multicolumn{2}{|c|}{ Female } & \multicolumn{2}{|c|}{ Male } & \multicolumn{2}{|c|}{ Female } \\
\hline & Comp. & Attempt & Comp. & Attempt & Comp. & Attempt & Comp. & Attempt & Comp. & Attempt & Comp. & Attempt \\
\hline Manufacturing & 0.011 & 0.017 & 0.000 & 0.001 & 0.001 & 0.001 & 0.000 & 0.000 & 0.000 & 0.000 & 0.000 & 0.000 \\
\hline Construction & 0.140 & 0.133 & 0.005 & 0.004 & 0.001 & 0.011 & 0.000 & 0.001 & 0.000 & 0.000 & 0.000 & 0.000 \\
\hline Health Tech & 0.196 & 0.095 & 0.351 & 0.169 & 0.019 & 0.014 & 0.027 & 0.031 & 0.000 & 0.000 & 0.000 & 0.001 \\
\hline Other Health & 0.092 & 0.068 & 0.113 & 0.064 & 0.016 & 0.035 & 0.079 & 0.100 & 0.026 & 0.023 & 0.109 & 0.100 \\
\hline Transportation & 0.007 & 0.006 & 0.001 & 0.001 & 0.005 & 0.003 & 0.001 & 0.000 & 0.000 & 0.000 & 0.000 & 0.000 \\
\hline $\begin{array}{l}\text { Business/ } \\
\text { Management }\end{array}$ & 0.031 & 0.029 & 0.091 & 0.060 & 0.005 & 0.025 & 0.010 & 0.026 & 0.284 & 0.242 & 0.175 & 0.157 \\
\hline Education & 0.002 & 0.002 & 0.029 & 0.052 & 0.000 & 0.002 & 0.005 & 0.012 & 0.029 & 0.031 & 0.120 & 0.114 \\
\hline Engineering & 0.061 & 0.056 & 0.021 & 0.021 & 0.034 & 0.050 & 0.007 & 0.011 & 0.168 & 0.168 & 0.026 & 0.025 \\
\hline Communications & 0.005 & 0.005 & 0.004 & 0.002 & 0.005 & 0.005 & 0.002 & 0.002 & 0.039 & 0.035 & 0.072 & 0.060 \\
\hline Legal & 0.000 & 0.003 & 0.001 & 0.004 & 0.407 & 0.108 & 0.383 & 0.133 & 0.005 & 0.003 & 0.007 & 0.006 \\
\hline Security & 0.408 & 0.266 & 0.219 & 0.120 & 0.009 & 0.021 & 0.005 & 0.011 & 0.049 & 0.043 & 0.037 & 0.034 \\
\hline $\begin{array}{l}\text { Bio, Math/Stats, } \\
\text { Physical Science }\end{array}$ & 0.007 & 0.005 & 0.003 & 0.002 & 0.003 & 0.003 & 0.002 & 0.003 & 0.071 & 0.076 & 0.068 & 0.079 \\
\hline Social Science & 0.000 & 0.000 & 0.001 & 0.001 & 0.000 & 0.001 & 0.001 & 0.004 & 0.192 & 0.164 & 0.210 & 0.190 \\
\hline Humanities & 0.010 & 0.025 & 0.008 & 0.027 & 0.488 & 0.592 & 0.475 & 0.524 & 0.108 & 0.117 & 0.130 & 0.129 \\
\hline Other & 0.030 & 0.028 & 0.149 & 0.082 & 0.004 & 0.007 & 0.003 & 0.004 & 0.025 & 0.024 & 0.039 & 0.034 \\
\hline Missing & 0.002 & 0.262 & 0.002 & 0.390 & 0.001 & 0.122 & 0.001 & 0.137 & 0.003 & 0.072 & 0.007 & 0.072 \\
\hline $\mathrm{N}$ & 7,193 & 15,348 & 4,867 & 13,427 & 16,631 & 63,492 & 26,605 & 80,739 & 17,235 & 31,568 & 28,329 & 45,460 \\
\hline
\end{tabular}


Table 4 (cont'd)

\section{By FRL status}

Manufacturing

Construction

Health Tech

Other Health

Transportation

Business/

Management

Education

Engineering

Communications

Legal

Security

Bio, Math/Stats,

Physical Science

Social Science

Humanities

Other

Missing

$\mathrm{N}$
FRL

$\begin{array}{cccc}\text { Comp. } & \text { Attempt } & \text { Comp. } & \text { Attempt } \\ 0.008 & 0.009 & 0.005 & 0.007 \\ 0.085 & 0.072 & 0.083 & 0.067 \\ 0.270 & 0.145 & 0.235 & 0.108 \\ 0.109 & 0.075 & 0.085 & 0.055 \\ 0.003 & 0.003 & 0.007 & 0.005 \\ 0.058 & 0.043 & 0.050 & 0.043 \\ 0.010 & 0.018 & 0.019 & 0.035 \\ 0.041 & 0.034 & 0.047 & 0.044 \\ 0.005 & 0.003 & 0.003 & 0.003 \\ 0.001 & 0.002 & 0.000 & 0.005 \\ 0.315 & 0.187 & 0.382 & 0.221 \\ 0.006 & 0.004 & 0.003 & 0.002 \\ 0.000 & 0.001 & 0.001 & 0.001 \\ 0.010 & 0.027 & 0.004 & 0.023 \\ 0.078 & 0.052 & 0.075 & 0.052 \\ 0.002 & 0.323 & 0.003 & 0.330 \\ 8,086 & 17,155 & 3,408 & 9,950\end{array}$

AA

Non-FRL

\section{Comp.}

0.001

0.001

0.024

0.054

0.002

0.007

0.003

0.017

0.003

0.391

0.007

0.003

0.000

0.484

0.003

0.001

31,537
Attempt

\subsection{1}

0.005

0.022

0.064

0.001

0.022

0.006

0.027

0.003

0.134

0.014

0.003

0.002

0.550

0.005

0.140

94,749
FRL

Comp.

0.001

0.000

0.025

0.060

0.002

0.012

0.005

0.018

0.003

0.394

0.007

0.001

0.001

0.468

0.003

0.001

9,819
Attempt

0.001

0.027
0.025

0.089

0.001

0.032

0.011

0.031

0.004

0.095

0.019

0.003

0.003

0.560

0.006

0.112

43,433
BA

Non-FRL

Comp. Attempt Comp.

$0.000 \quad 0.000$

$0.000 \quad 0.000$

$0.000 \quad 0.000$

$0.074 \quad 0.064$

$0.000 \quad 0.000$

0.217

0.087

0.080

0.063

0.006

0.038

0.069

0.199

0.127

0.035

0.005

36,272

\subsection{4}

0.081

0.084

0.053

0.005

0.035

0.077

0.178

0.130

0.031

0.067

58,861
FRL

$0.000 \quad 0.000$

$0.000 \quad 0.000$

$0.000 \quad 0.001$

$0.102 \quad 0.086$

$0.000 \quad 0.000$

0.206

0.079

0.076

0.042

0.006

0.061

0.071

0.224

0.094

0.028

0.010

7,085
0.176

0.077

0.084

0.035

0.004

0.051

0.082

0.184

0.097

0.026

0.098

14,714 
Table 4 (cont'd)

D. By HS achievement

Voc/Cert

Top Bottom

$\begin{array}{cccc}\text { Comp. } & \text { Attempt } & \text { Comp. } & \text { Attempt } \\ 0.006 & 0.007 & 0.007 & 0.008 \\ 0.061 & 0.051 & 0.082 & 0.066 \\ 0.271 & 0.160 & 0.257 & 0.127 \\ 0.123 & 0.085 & 0.080 & 0.060 \\ 0.002 & 0.001 & 0.004 & 0.004 \\ 0.058 & 0.042 & 0.050 & 0.041 \\ 0.009 & 0.010 & 0.017 & 0.027 \\ 0.057 & 0.040 & 0.030 & 0.033 \\ 0.006 & 0.004 & 0.003 & 0.003 \\ 0.001 & 0.001 & 0.000 & 0.003 \\ 0.317 & 0.194 & 0.369 & 0.207 \\ 0.006 & 0.004 & 0.005 & 0.003 \\ 0.000 & 0.001 & 0.001 & 0.001 \\ 0.011 & 0.021 & 0.007 & 0.028 \\ 0.070 & 0.046 & 0.084 & 0.054 \\ 0.002 & 0.332 & 0.003 & 0.334 \\ 4,634 & 8,300 & 4,152 & 10,652\end{array}$

AA

Top Bottom

Comp.

0.000

0.001

0.021

0.055

0.002

0.007

0.002

0.019

0.003

0.383

0.006

0.002

0.000

0.496

0.003

0.000

23,083

Attempt

0.004

0.017

0.053

0.001

0.020

0.004

0.027

0.003

0.160

0.010

0.003

0.002

0.514

0.004

0.177

56,300
Comp.

\subsection{1}

0.000

0.025

0.056

0.003

0.010

0.006

0.016

0.004

0.404

0.010

0.003

\subsection{1}

0.455

0.005

0.000

10,143
Attempt

0.001

0.005

0.029

0.090

0.001

0.029

0.011

0.027

0.004

0.094

0.021

0.003

0.003

0.582

0.007

0.093

46,688
BA

Top

Comp.
0.000
0.000
0.000
0.074
0.000

Attempt

0.000

0.000

0.000

0.065

0.000

0.199

0.074

0.097

0.051

0.005

0.031

0.086

0.174

0.125

0.031

0.061

48,448

\section{Bottom}

Comp. Attempt

$0.000 \quad 0.000$

$0.000 \quad 0.000$

$0.000 \quad 0.001$

$0.106 \quad 0.090$

$0.000 \quad 0.000$

$0.167 \quad 0.146$

$0.111 \quad 0.105$

$0.028 \quad 0.038$

$0.063 \quad 0.049$

$0.008 \quad 0.006$

$0.082 \quad 0.066$

$\begin{array}{ll}0.030 & 0.047\end{array}$

$0.237 \quad 0.203$

$0.125 \quad 0.115$

$0.033 \quad 0.030$

$0.011 \quad 0.104$

$5,803 \quad 12,075$ 
Table 5 - Regression Results for Log Quarterly Earnings: All Workers

(1)

(2)

(3)

(4)

(5)

Highest Credential

No HS

$\begin{array}{lll}-0.15 * * * & -0.13 * * * & -0.11 * * *\end{array}$

$-0.11 * * *$

$-0.11 * * *$

Voc_Cert

$(0.00)$

$0.31 * * *$

$(0.00)$

$(0.01)$

$0.26 * * *$

(0.00)

$0.29 * * *$

(0.00)

$0.18^{* * *}$

(0.00)

AA

$0.34 * * *$

(0.01)

(0.01)

(0.01)

$0.18^{* * *}$

(0.01)

$0.37 * * *$

$0.40^{* * * *}$

$0.10^{* * *}$

(0.01)

AS

(0.01)

(0.01)

(0.01)

$0.03 * *$

AS

BA

$0.61 * * *$

$0.69 * * *$

$0.78^{* * *}$

(0.01)

MA_PhD

(0.01)

$0.90^{* * * *}$

$0.99 * * *$

(0.01)

$1.09 * * *$

(0.01)

$0.29 * * *$

(0.02)

Work Experience

(0.01)

$0.02 * * *$

(0.01)

$0.02 * * *$

(0.01)

$0.02 * * *$

(0.00)

$(0.00)$

Work Experience2

$-0.00 * * *$

$-0.00 * * *$

(0.00)

Tenure

$0.08 * * *$

$(0.00)$

$0.08 * * *$

(0.00)

Tenure2

$-0.00 * * *$

(0.00)

$(0.00)$

FCAT

$0.06 * * *$

$-0.00 * * *$

$(0.00)$

$-0.00 * * *$

$0.39 * * *$

$0.39 * * *$

(0.01)

(0.01)

$0.66^{* * * *}$

$0.66^{* * * *}$

Female

$(0.00)$

$-0.15 * * *$

$(0.00)$

$0.05 * * *$

$(0.00)$

$0.08^{* * * *}$

(0.02)

$0.02^{* * * *}$

(0.02)

$0.02 * * *$

(0.00)

(0.00)

$-0.00 * * *$

$-0.00 * * *$

$(0.00)$

(0.00)

$0.08 * * *$

$0.08 * * *$

$(0.00)$

(0.00)

(0.00)

$-0.00 * * *$

$-0.00 * * *$

$-0.00 * * *$

(0.00)

(0.00)

(0.00)

$0.05^{* * *}$

$0.04 * * *$

$0.04 * * *$

(0.00)

(0.00)

$-0.15^{* * * *}$

(0.00)

(0.00)

(0.00)

$-0.15^{* * * *}$

$-0.16^{* * *}$

$-0.16^{* * *}$

(0.00)

(0.00)

(0.00)

(0.00)

$-0.07 * * *$

$-0.07 * * *$

$-0.06^{* * *}$

$-0.06 * * *$

$-0.06 * * *$

(0.00)

Black

$-0.11 * * *$

(0.00)

(0.00)

$-0.12 * * *$

(0.00)

(0.00)

(0.00)

$-0.12 * * *$

$-0.11 * * *$

$-0.11 * * *$

(0.00)

(0.00)

(0.00)

Hispanic

$0.15^{* * *}$

$0.15 * * *$

$0.14^{* * *}$

$0.15 * * *$

$0.15^{* * * *}$

$(0.00)$

0.08 ***

(0.00)

(0.00)

0.07 ***

$0.07 * * *$

(0.00)

(0.00)

$(0.01)$

(0.01)

$-0.08 * * *$

$-0.08 * * *$

(0.01)

$-0.08 * * *$

0.06 ***

$0.06^{* * *}$

(0.02)

(0.02)

(0.01)

(0.01)

$-0.08 * * *$

(0.01)

$-0.08 * * *$

CC Credits

0 credits

$0.19 * * *$

(0.01)

1-15 credits

$0.28 * * *$

(0.01)

$0.28 * * *$

(0.01)

$0.30^{* * * *}$

(0.01)

$0.32 * * *$

(0.01) 


\section{Table 5 (cont'd)}

60-80 credits

University Credits

0 credits

1-30 credits

$31-60$ credits

$61-90$ credits

91-120 credits

$121-150$ credits

Post-secondary Credits

Earned (100s)

$\mathrm{CC}$ credits

University credits

Post-secondary GPA

Post-secondary Credits (100s)

Math

Science

Observations

R-squared
$3,739,354$
0.36

$0.32 * * *$

$(0.01)$

0.02

(0.03)

$0.27 * * *$

(0.01)

$0.34 * * *$

(0.01)

$0.41 * * *$

(0.02)

$0.48 * * *$

(0.03)

$0.55 * * *$

(0.03)
$0.57 * * *$

$(0.01)$

$0.47 * * *$

(0.01)

$\begin{array}{cc}0.21 * * * & 0.20 * * * \\ (0.01) & (0.01) \\ 0.23 * * * & 0.24 * * * \\ (0.01) & (0.01) \\ 0.10^{* * *} & 0.10 * * * \\ (0.00) & (0.00)\end{array}$

$0.42 * * *$

$0.49 * * *$

(0.04)

0.16 ***

(0.04)

(0.02)

$0.16 * * *$

$3,739,354$

0.36
$3,739,354$

0.36
(0.02)

3,739,354

0.36

Notes: $* * * \mathrm{p}<0.01, * * \mathrm{p}<0.05, * \mathrm{p}<0.1$. The dependent variable is $\ln$ (quarterly earnings). Robust standard errors are in parentheses. FCAT scores are standardized to mean 1, standard deviation 0. Postsecondary GPA is measured on a 4 point scale. 


\section{Table 6 - Regression Results for Fields of Study: By Level of Education}

Highest Credential

$$
\text { No HS }
$$

Voc_Cert

AA \& Below

BA \& Above

AA

$-0.12 * * *$

$(0.01)$

$-0.05$

$(0.12)$

0.19

$(0.12)$

BA

MA_PhD

Completed field of study

Manufacturing

Construction

Health Tech

Other Health

Transportation

Business/Management

Education

Engineering

Communications

Legal

Security

Bio, Math/Stats, Phys Sci

Social Science

Other

No CIP

Work Experience

Work Experience ${ }^{2}$

Tenure

$0.26 * * *$

$0.25 * * *$

$0.23 * * *$

$0.48 * * *$

$0.30 * *$

$0.08 *$

$-0.38 * * *$

0.06

$-0.21 * *$

$-0.01$

$0.32 * * *$

$0.15^{* *}$

$-0.80 * * *$

$-0.08 *$

0.02

$0.02 * * *$

(0.00)

$-0.00 * * *$

(0.00)

$0.08 * * *$

(0.00)

Tenure $^{2}$

$-0.00 * * *$

(0.00)

FCAT

$0.06^{* * * *}$

(0.00)

Female

$-0.13 * * *$

(0.01)

$-0.05 * * *$

(0.01)

$-0.08 * * *$

Black

Hispanic

(0.01)

$0.15^{* * *}$

(0.01)

$0.40 * * *$

(0.09)

0.31 ***

(0.07)

$0.48 * * *$

(0.07)

$0.73 * * *$

(0.07)

$-1.88 * * *$

$0.29^{*}$

$0.16^{* *}$

$0.39 * * *$

$0.81 * * *$

$0.29 * * *$

$0.03 *$

$0.47 * * *$

$0.15^{* * * *}$

$0.11 * * *$

$0.07 * * *$

$0.20 * * *$

$0.07 * * *$

$0.13 * * *$

$0.31 * * *$

$0.02 * * *$

$(0.00)$

$-0.00 * * *$

$(0.00)$

$0.05 * * *$

(0.00)

$-0.00 * * *$

(0.00)

$0.06^{* * * *}$

(0.01)

$-0.08 * * *$

(0.01)

$-0.02 *$

(0.01)

$-0.07 * * *$

(0.01)

$0.08^{* * * *}$

(0.01) 
Table 6 (cont'd)

Asian

Other

Observations

R-squared
0.03
$(0.02)$
$-0.08 * *$
(0.03)
$-0.01$
(0.02)
$-0.01$
(0.05)

Notes: $* * * \mathrm{p}<0.01, * * \mathrm{p}<0.05, * \mathrm{p}<0.1$. The dependent variable is $\ln$ (quarterly earnings). Robust standard errors are in parentheses. FCAT scores are standardized to mean 1, standard deviation 0 . Controls for demographics are included but not reported. 


\section{Table 7 - Regression Results: by Demographic and FCAT Groups}

Gender

Male Female

Highest Credential

No HS

Voc_Cert

AA

BA

MA_PhD

Work Experience

Work Experience ${ }^{2}$

Tenure

Tenure $^{2}$

FCAT

FRL

Female

Black

Hispanic

Asian

Other

Observations

R-squared

$-0.12 * * *$
$(0.00)$
$0.35 * * *$
$(0.01)$
$0.30 * * *$

(0.01)

$0.64 * * *$

(0.01)

1.03 ***

(0.02)

$0.02 * * *$

(0.00)

$-0.00 * * *$

(0.00)

$0.08^{* * * *}$

(0.00)

$-0.00 * * *$

(0.00)

$0.05^{* * *}$

(0.00)

$-0.06^{* * * *}$

(0.00)

$-0.18 * * *$

(0.00)

$0.11 * * *$

(0.00)

$0.03 * *$

(0.01)

$-0.14 * * *$

(0.02)

2,096,183

0.35
$-0.19 * * *$

(0.00)

$0.22 * * *$

(0.02)

$0.35^{* * * *}$

(0.01)

$0.58 * * *$

(0.01)

$0.82^{* * * *}$

(0.02)

(0.00)

$-0.00 * * *$

(0.00)

$0.07 * * *$

(0.00)

$-0.00 * * *$

(0.00)

0.07 ***

(0.00)

$-0.09 * * *$

(0.00)

$-0.03 * * *$

(0.00)

$0.21^{* * *}$

(0.00)

$0.13^{* * *}$

(0.02)

$-0.00$

(0.02)

$1,656,973$

0.37
$0.02 * * *$
FRL

No

$-0.14 * * *$
$(0.00)$
$0.29 * * *$
$(0.01)$
$0.31 * * *$

0.31 ***

(0.01)

$0.59 * * *$

(0.01)

$0.86^{\text {**** }}$

(0.01)

$0.02 * * *$

$(0.00)$

$-0.00 * * *$

(0.00)

0.07 ****

$(0.00)$

$-0.00 * * *$

(0.00)

$0.07 * * *$

(0.00)

$-0.15^{* * *}$

(0.00)

$-0.13 * * *$

(0.00)

$0.11 * * *$

(0.00)

$0.05^{* * * *}$

(0.01)

$-0.10^{* * * *}$

(0.02)

$2,196,457$

0.36

$-0.16 * * *$
$(0.00)$
$0.35 * * *$
$(0.02)$
$0.41 * * *$

$0.41 * * *$

(0.02)

$0.69 * * *$

(0.01)

$1.03 * * *$

(0.04)

$0.02 * * *$

(0.00)

$-0.00 * * *$

(0.00)

$0.08 * * *$

(0.00)

$-0.00 * * *$

(0.00)

$0.05^{* * * *}$

(0.00)

$0.15^{* * * *}$

(0.00)

$-0.08 * * *$

(0.00)

0.20 ***

(0.00)

$0.13 * * *$

(0.02)

$-0.05^{* *}$

(0.02)

$1,556,699$

0.33
FCAT

Bottom

Top Half Half

$\begin{array}{cc}-0.11 * * * & -0.15^{* * *} \\ (0.01) & (0.00) \\ 0.24 * * * & 0.34 * * * \\ (0.02) & (0.01) \\ 0.25 * * * & 0.42^{* * *}\end{array}$

(0.01)

$0.51 * * *$

(0.01)

$0.69 * * *$

(0.01)

(0.01)

$0.79 * * *$

$0.96^{* * * *}$

(0.02)

$(0.03)$

$0.02 * * *$

$0.02^{* * *}$

(0.00)

$-0.00 * * *$

(0.00)

(0.00)

$0.06^{* * * *}$

$-0.00 * * *$

(0.00)

$0.08 * * *$

$(0.00)$

$-0.00 * * *$

$(0.00)$

$-0.00 * * *$

(0.00)

$(0.00)$

$0.07 * * *$

$0.05^{* * *}$

(0.01)

(0.00)

$-0.13 * * *$

$-0.15^{* * * *}$

(0.00)

(0.00)

$-0.06 * * *$

$-0.07 * * *$

(0.01)

(0.00)

$-0.08 * * *$

$-0.12 * * *$

(0.01)

(0.00)

$0.13 * * *$

$0.16^{* * *}$

(0.01)

(0.00)

$0.06^{* * * *}$

$0.07 * * *$

(0.02)

(0.01)

$-0.03$

$-0.10 * * *$

(0.03)

(0.02)

$1,052,977 \quad 2,700,179$

0.35

0.33

Notes: $* * * \mathrm{p}<0.01, * * \mathrm{p}<0.05, * \mathrm{p}<0.1$. The dependent variable is $\ln$ (quarterly earnings). Robust standard errors are in parentheses. FCAT scores are standardized to mean 1, standard deviation 0 . 